\title{
The physiological and psychological relaxing effects of viewing rose flowers in office workers
}

\author{
Harumi Ikei ${ }^{1}$, Misako Komatsu', Chorong Song ${ }^{1}$, Eri Himoro ${ }^{2}$ and Yoshifumi Miyazaki ${ }^{*}$
}

\begin{abstract}
Background: In recent years, the physiological relaxing effect brought by nature is becoming clear; however, many workers find it difficult to be exposed to nature in their working environment. Exposure to fresh flowers represents an opportunity to incorporate nature into their working lives. In this study, we examined the effects of exposure to roses on physiological and psychological variables (heart rate variability, pulse rate, and subjective responses) in office workers.

Results: The experimental site was Mizuho Information \& Research Institute, Inc., in the Tokyo metropolitan area. Thirty-one male office workers were included in the present study. The subjects were exposed to thirty unscented pink roses (Rosa, Dekora) arranged in a cylindrical glass vase for 4 min. In the control condition, the subjects were not exposed to flowers. After the experiments, the subjects completed a questionnaire. The order of exposure was counterbalanced among subjects. Among subjects exposed to roses, the high-frequency component of heart rate variability was significantly higher than in controls. Similarly, 'comfortable, 'relaxed' and 'natural' feelings were more common in subjects exposed to roses.
\end{abstract}

Conclusions: Data from this study support the presence of physiological and psychological relaxing effects of being exposed to flowers on office workers.

Keywords: Fresh rose flowers, Office workers, Visual stimuli, Heart rate variability, Pulse rate

\section{Background}

Ever increasing urbanization and job pressures have resulted in an overly stressed society far removed from potential calming effects of nature [1]. The disconnect between this state of permanent urban stress and our evolutionary history in the natural world was encapsulated by Miyazaki et al. [1]: "We have become the humans we are today, living in a modern civilization, through a process of evolution that took place in a natural environment. The human body is thus made to adapt to nature. However, as conveyed through terms such as 'techno-stress', artificialisation is taking place at such a rapid rate that we now find ourselves in stressful situations in our daily lives and are forced to deal with the resultant pressures [1]". We hypothesise that modern people in stressful states can be relaxed through contact with nature.

In our stressful modern societies, the relaxing effect of natural stimuli is considered advantageous compared

\footnotetext{
* Correspondence: ymiyazaki@faculty.chiba-u.jp

'Center for Environment, Health and Field Sciences, Chiba University, Chiba, Japan Full list of author information is available at the end of the article
}

with other stimuli. Many people are thus attracted to the physiological and psychological relaxing effect of exposure to nature. Field experiments on forest bathing [2-10], urban parks [11] and rooftop gardens [12] have demonstrated physiological relaxing effects of contact with nature. Furthermore, Li et al. reported forest bathing increased natural killer cell function and improved immune function [13]. This effect was sustained for approximately 1 month. The results of these studies suggest that contact with nature is a type of prophylaxis.

Globally, evidence-based medicine has been attracting attention, with physiological data from field tests offering great value. We expect that accumulating physiological data from field experiments will continue to demonstrate preventive medical effects of nature therapy in the future $[1,14]$.

In modern society, many people spend the majority of their time in intensely stressful states, and have no time for contact with nature outside of their immediate surroundings. Office workers who work in urban areas are typical examples. Previous studies have evaluated the 
psychological stress levels among office workers [15], and they have shown that stressors at work not only cause psychological symptoms but also increase risk of cardiovascular disease [16] and conditions such as insomnia [17]. Moreover, data reported by the National Police Agency indicate that work problems were responsible for $8.2 \%$ cases of suicide in Japan in 2010 [18]. Therefore, because many office workers work in highly stressful environments, it might be argued that alleviating this situation is matter of urgency. However, most previous studies [2-10] had male college students as subjects, and there are few studies of office workers aged 20 to 50 years.

Flower arrangements are familiar to many people as bringing nature into daily life and offer office workers easy contact with nature within the constraints of time and space. In the Japanese flower market, chrysanthemum is the most popular flower type, with the most popular flowers being carnations and roses [19]. Because chrysanthemums are usually laid for the deceased, roses are one of the most preferred flowers in Japan. The relaxing effects of fresh flowers such as roses are empirically known. There are many studies of psychological effects of exposure to flowers, but none have objectively studied the physiological effects of such exposure. We propose that flower arrangements may contribute to improving the stress in daily life from the viewpoint of preventive medicine. The aim of this research is to clarify the physiological and psychological relaxing effects of exposure to rose flowers on male office workers experiencing high levels of stress.

\section{Methods}

The experiments were conducted in a conference room of the Mizuho Information \& Research Institute, Inc. The room temperature was maintained at $24.6^{\circ} \mathrm{C} \pm 1.8^{\circ} \mathrm{C}$ (control room, $25.2^{\circ} \mathrm{C} \pm 0.7^{\circ} \mathrm{C}$ ) and relative humidity was maintained at $31.6 \% \pm 3.9 \%$ (control room, $29.7 \% \pm$ $1.8 \%)$. Thirty-one male workers $(37.3 \pm 2.0$ years old $)$ working in the institute were included. The study was conducted with the approval of the Ethics Committee of the Center for Environment, Health and Field Sciences, Chiba University and all subjects provided written informed consent.

Thirty fresh and unscented (sensory intensity was classed as unscented on testing) pink roses (Rosa, cultivar name: Dekora) trimmed to a length of $40 \mathrm{~cm}$ were used for viewing. The roses were arranged in a cylindrical glass vase $12 \mathrm{~cm}$ in diameter and $20 \mathrm{~cm}$ in height. The distance from subjects' eyes to the flowers was 37 to $40 \mathrm{~cm}$, and it was adjusted according to the height of the subjects. The experimental setting is shown in Figure 1.

We explained the experimental protocol to subjects in the waiting room, after which they received 4 minutes of viewing roses. The control group was not exposed to flowers in another room. After the experiments, subjects

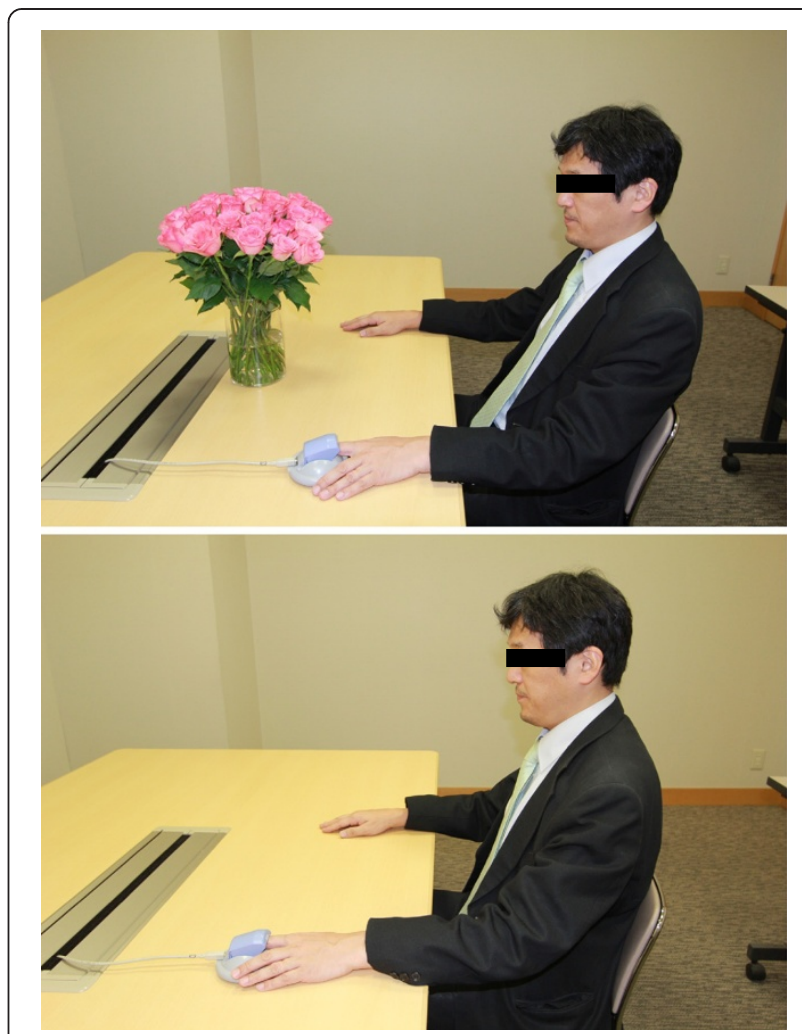

Figure 1 Experimental setting. The physiological indices of a subject sitting in the viewing area of the roses and control are being measured.

filled a questionnaire. The order of stimuli was counterbalanced among subjects.

Previous studies have reported that the a-a intervals of the acceleration plethysmograph (APG) and the R-R intervals of electrocardiographs are highly correlated [20]. Therefore, heart rate variability (HRV) was calculated by spectral analysis of the coefficient of the variation of the a-a intervals of an APG shown in Figure 2 (ARTETT, UMedica Inc., Osaka, Japan). The pulse rate was converted by

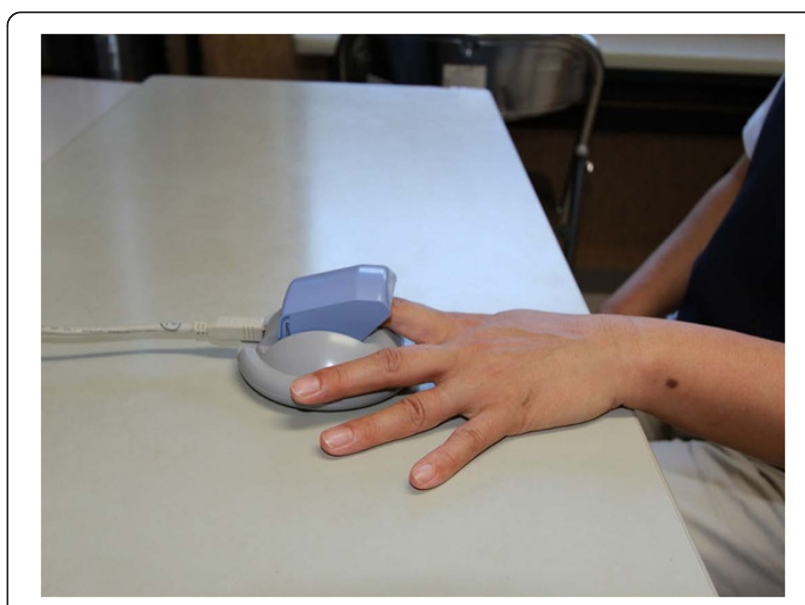

Figure 2 An example of the fingertip pulse wave. 
dividing 60 with a-a intervals of APG. The sampling frequency was set at 1,000 $\mathrm{Hz}$. The maximum entropy method was used for frequency analysis, and variance of the lowfrequency (LF) band (0.04 to $0.15 \mathrm{~Hz}$ ) and high-frequency (HF) band (0.15 to $0.40 \mathrm{~Hz})$ were calculated. The LF/HF ratio for R-R interval variability was also assessed. The HF component was used as an index of parasympathetic nervous activity and the LF/HF ratio was as an index of sympathetic nervous activity [21]. The HRV and pulse rate data were collected continuously during the 4 minutes of the experiments and an average was calculated over 4 minutes.

For psychological evaluations, we employed a 13-point rating scale including the following parameters: 'comfortableuncomfortable,' 'relaxed-awakening' and 'natural-artificial' along with the factors in the profile of mood states (POMS) questionnaire. The POMS questionnaire simultaneously evaluates six measures of mood: tension-anxiety (T-A), depression-dejection (D), anger-hostility (A-H), fatigue $(\mathrm{F})$, confusion $(\mathrm{C})$, and vigor $(\mathrm{V})$. In this study, were used the Japanese version of POMS [22-24] consisting of 30 items.

The Statistical Package for Social Sciences software (v20.0, SPSS Inc., Chicago, IL, USA) was used for all statistical analyses. Statistical analysis of physiological data was performed using the paired $t$-test after calculating the average values obtained during the 4-minute viewing of the roses versus those obtained during the control condition. Psychological evaluation was analyzed by the Wilcoxon signed-rank test. Statistical differences were considered significant at $P<0.05$.

\section{Results and discussion}

Figure 3 shows the HF component of HRV. The HF component was $502.4 \mathrm{msec}^{2}$ during rose flower viewing,

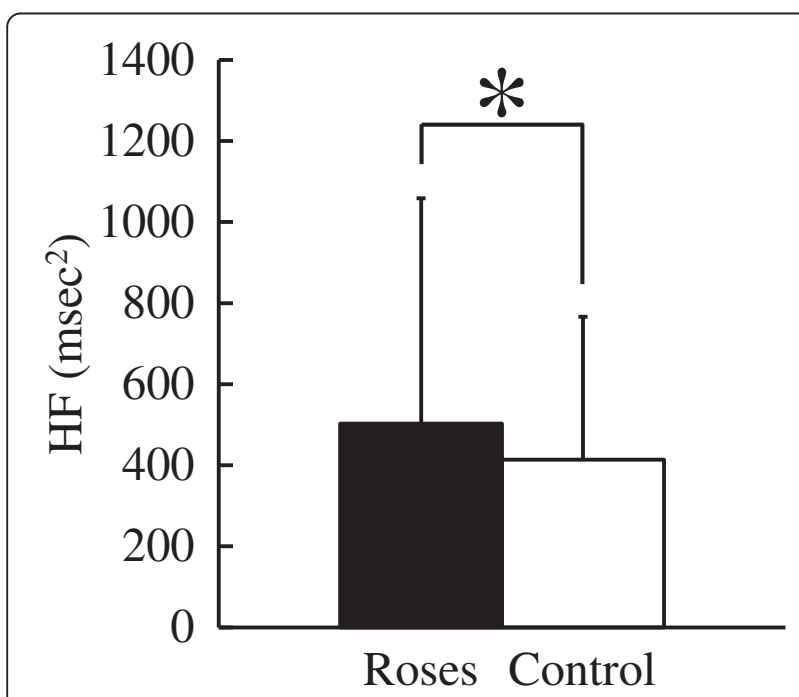

Figure 3 Comparison of the mean values of the high-frequency (HF) component between the rose flower exposure and control condition. $\mathrm{N}=31$; mean $\pm \mathrm{SD}$; ${ }^{*} P<0.05$; significant differences verified by paired $t$-test.

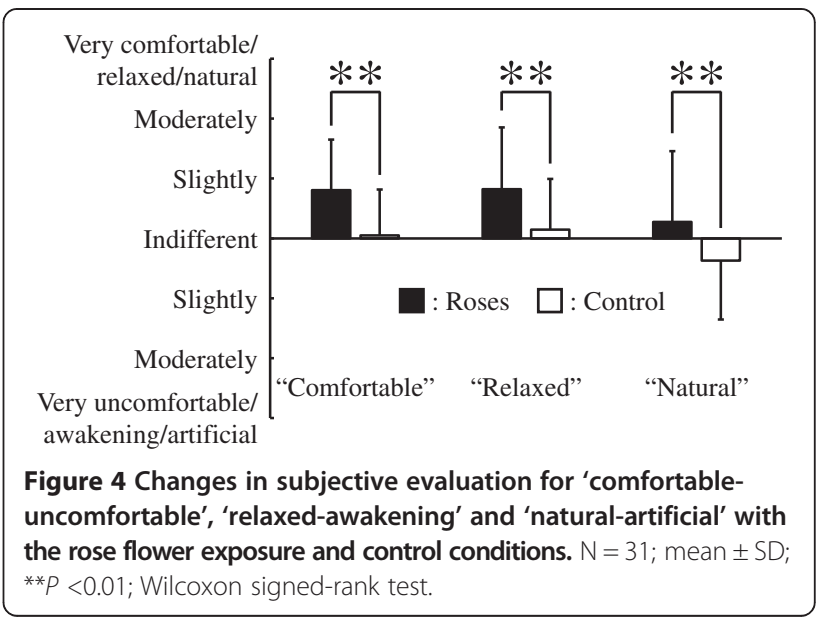

and $414.0 \mathrm{msec}^{2}$ in the control condition; it showed 21\% significant increase $(p<0.05)$ on exposure to roses, meaning that parasympathetic nervous activity was significantly higher while viewing the roses. There were no significant differences in LF/HF of HRV or pulse rate.

Figure 4 shows results of comfortable, relaxed and natural states in the subjective evaluation by the questionnaires. Subjects reported being significantly more comfortable being exposed to roses than in the control condition $(P<0.01)$. Relaxed and natural states were also significantly more frequent on exposure to roses than in the control condition $(P<0.01)$. Figure 5 shows results of the POMS questionnaire survey. Scores of T-A, F and $\mathrm{C}(P<0.01)$ as well as those of D and A-H $(P<0.05)$ were significantly lower on viewing roses than in the control condition. On the other hand, V scores during the rose viewing were significantly higher than in the control condition $(P<0.01)$.

In the present study, we evaluated changes in autonomic nervous system activity, a physiological measure of stress, in office workers while viewing common fresh

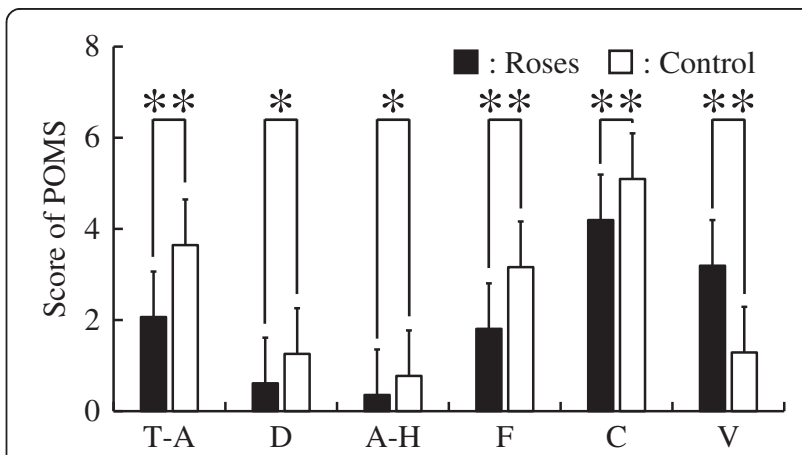

Figure 5 Subscale scores for the profile of mood states (POMS) scale during the rose flower exposure and control conditions. $\mathrm{N}=31$; mean $\pm \mathrm{SD}$; ${ }^{* *} P<0.01$; ${ }^{*} P<0.05$; Wilcoxon signed-rank test. A-H, anger-hostility; C, confusion; D, depression-dejection; F, fatigue; $\mathrm{T}-\mathrm{A}$, tension-anxiety; $\mathrm{V}$, vigor. 
roses [19]. A relatively brief (4-minute) viewing session resulted in significantly increased parasympathetic nervous activity, concordant with several previous studies demonstrating enhanced parasympathetic activity while viewing a forest scene $[2,3,6,7,9]$. Furthermore, this result is consistent with our previous report demonstrating calming effects of roses in middle-aged and elderly medical staff [25] and in high-school students [26].

Numerous studies have evaluated effects of contact with familiar natural environments on human physiology and emotions. Indoor plants and the view from the window are good examples of the contact with nature obtainable while inside a room, and positive results of their physiological and psychological effects have been demonstrated [27-31]. In the previous studies, it is reported that natural views from hospital rooms or indoor plants hasten recovery of patients after surgery and decrease systolic blood pressure [27-29]. Those effects in an office location have been studied, showing greater work efficiency and job satisfaction simply by placing indoor plants in the office [30,31]. Furthermore, the higher the stress state, the more effective the nature therapy [32].

Our research showed that parasympathetic nervous activity was enhanced by viewing roses. Therefore, by simple stimulus, roses possibly offer preventive medical effects [14] by decreasing stress. Elucidation of the interaction of humans with the natural environment is an important issue in physiological anthropology. The results of this study may have important implications in the work place and for the health of office workers.

This study had a few limitations. First, only male subjects were included, and only roses were viewed. In future experiments, we will examine the responses of female subjects exposed to multiple types of flowers. We predict that the physiological data will support the physiological and psychological relaxing effects of exposure to roses, which may consequently lead to the increased use of flowers to reduce office-related stress. Second, we only evaluated HRV; therefore, this study cannot be considered to be a complete physiological evaluation. Other experimental indices, such as brain activity and stress hormone levels, should be assessed to determine the effects of visual stimulation such as viewing roses on responses in humans.

\section{Conclusions}

Parasympathetic nervous activity was enhanced by viewing roses. This finding suggests a simple method for decreasing stress and improving the health of office workers.

\section{Abbreviations}

A-H: anger-hostility; APG: acceleration plethysmograph; C: confusion; D: depression-dejection; F: fatigue; HF: high frequency; HRV: heart rate variability; LF: low frequency; POMS: profile of mood states; T-A: tension-anxiety; V: vigor

\section{Competing interests}

The authors declare that they have no competing interests.

\section{Authors' contributions}

HI contributed to the experimental design, data acquisition, statistical analysis, interpretation of the results and manuscript preparation. MK and CS contributed to acquisition and interpretation of data. EH designed the study and participated in data acquisition. YM had an important role in this research, particularly in study design, interpretation of data and manuscript preparation. All authors contributed to manuscript preparation and are responsible for the final editing and approval of the manuscript.

\section{Acknowledgments}

This work was supported by a grant from the Policy Research Institute, Ministry of Agriculture, Forestry and Fisheries (Extramural Research Program for Agricultural, Forestry and Fishery Policy Research). In addition, we appreciate the help of Kimiko Ishikawa (Senior Executive Advisor of the Japan Florists' Telegraph Delivery Association) for assistance in the selection and arrangement of fresh roses.

\section{Author details}

${ }^{1}$ Center for Environment, Health and Field Sciences, Chiba University, Chiba, Japan. ${ }^{2}$ Mizuho Information \& Research Institute, Inc, Tokyo, Japan.

Received: 6 December 2013 Accepted: 21 February 2014

Published: 8 March 2014

\section{References}

1. Miyazaki Y, Park BJ, Lee J: Nature therapy. In Designing our Future: Loca Perspectives on Bioproduction, Ecosystems and Humanity. Edited by Osaki M, Braimoh A, Nakagami K. Tokyo: United Nations University Press; 2011:407-412.

2. Park BJ, Tsunetsugu Y, Ishii H, Furuhashi S, Hirano H, Kagawa T, Miyazaki Y: Physiological effects of Shinrin-yoku (taking in the atmosphere of the forest) in a mixed forest in Shinano Town, Japan. Scand J Forest Res 2008, 23:278-283.

3. Lee J, Park BJ, Tsunetsugu Y, Kagawa T, Miyazaki Y: The restorative effects of viewing real forest landscapes: based on a comparison with urban landscapes. Scand J Forest Res 2009, 24:227-234

4. Park BJ, Tsunetsugu Y, Kasetani T, Morikawa T, Kagawa T, Miyazaki Y: Physiological effects of forest recreation in a young conifer forest in Hinokage town, Japan. Silva Fenn 2009, 43:291-301.

5. Tsunetsugu Y, Park BJ, Miyazaki Y: Trends in research related to "Shinrin-yoku" (taking in the forest atmosphere or forest bathing) in Japan. Environ Health Prevent Med 2010, 15:27-37.

6. Lee J, Park BJ, Tsunetsugu Y, Ohira T, Kagawa T, Miyazaki Y: Effect of forest bathing on physiological and psychological responses in young male subjects. Public Health 2011, 125:93-100.

7. Park BJ, Tsunetsugu Y, Lee J, Miyazaki Y: Effect of the forest environment on physiological relaxation - the results of field tests at 35 sites throughout Japan. In Forest Medicine. Edited by Li Q. New York: Nova; 2011:55-65.

8. Park BJ, Furuya K, Kasetani T, Miyazaki Y: Psychological evaluation of forest environment and the physical variation. In Forest Medicine. Edited by Li Q. New York: Nova; 2011:35-51.

9. Tsunetsugu Y, Park BJ, Miyazaki Y: Physiological effects of visual, olfactory, auditory, and tactile factors in the forest environment. In Forest Medicine. Edited by Li Q. New York: Nova; 2011:169-181.

10. Tsunetsugu Y, Lee J, Park BJ, Tyrvainen L, Kagawa T, Miyazaki Y: Physiological and psychological effects of viewing urban forest landscapes assessed by multiple measurement. Landsc Urban Plan 2013, 113:90-93.

11. Song C, Joung D, Ikei H, lgarashi M, Aga M, Park BJ, Miwa M, Takagaki M, Miyazaki Y: Physiological and psychological effects of walking on young males in urban parks in winter. J Physiol Anthropol 2013, 32:18.

12. Matsunaga $K$, Park BJ, Kobayashi H, Miyazaki Y: Physiological effect of a hospital rooftop forest on elderly women requiring care. J Am Geriatr SoC 2011, 59:2162-2163.

13. Li Q, Morimoto K, Kobayashi M, Inagaki H, Katsumata M, Hirata Y, Hirata K, Suzuki H, Li YJ, Ohira T, Matsui N, Kagawa T, Miyazaki Y, Krensky AM: Visiting forest, but not a city, increases human natural killer activity and expression of anti-cancer proteins. Int J Immunopathol Pharmacol 2008, 21:117-127 
14. Lee J, Li Q, Tyrväinen L, Tsunetsugu Y, Park BJ, Kagawa T, Miyazaki Y: Nature therapy and preventive medicine. In Public Health - Social and Behavioral Health. Edited by Maddock JR. New York: InTech Publishing; 2012:325-350.

15. Kawakami N, Haratani T: Epidemiology of job stress and health in Japan: review of current evidence and future direction. Ind Health 1999, 37:174-186.

16. Kang MG, Koh SB, Cha BS, Park JK, Baik SK, Chang SJ: Job stress and cardiovascular risk factors in male workers. Prev Med 2005, 40:583-588.

17. Ota A, Masue T, Yasuda N, Tsutsumi A, Mino Y, Ohara H: Association between psychosocial job characteristics and insomnia: an investigation using two relevant job stress models - the demand-control-support (DCS) model and the effort-reward imbalance (ERI) model. Sleep Med 2005, 6:353-358.

18. National Police Agency: Documents of Overview Related to Suicide in 2010 Tokyo: Community Safety Bureau, Community Safety Planning Division; 2011 [in Japanese]

19. Division S, Minister's Secretariat of Ministry of Agriculture, Forestry and Fisheries: 3 Marketing quantity and price of vegetables, fruits and flowers. In The 86th ministry of agriculture, forestry and fisheries statistics table (2010-2011). Tokyo: Association of Agriculture and Forestry Statistics, 2012:557-560

20. Takada H, Okino K: An evaluation method for heart rate variability by using acceleration plethysmography. Health Eval Promot 2004, 3:547-551.

21. Sawada Y, Ohtomo N, Tanaka Y, Tanaka G, Yamakoshi K, Terachi S, Shimamoto K, Nakagawa M, Satoh S, Kuroda S, limura O: New technique for time series analysis combining the maximum entropy method: its value in heart rate variability analysis. Med Biol Eng Comput 1997, 35:318-322.

22. McNair D, Lorr M: An analysis of mood in neurotics. J Abnorm Soc Psych 1964, 69:620-627.

23. Yokoyama K, Araki S, Kawakami K, Takeshita T: Production of the Japanese edition of profile of mood states (POMS): assessment of reliability and validity [Article in Japanese, English abstract]. Jpn J Hyg 1990, 37:913-918.

24. McNair D, Lorr M, Droppleman L: Manual for the profile of mood states. In Educational and Industrial Testing Service. Educational and Industrial Testing Services: San Diego; 1971

25. Komatsu M, Matsunaga K, Lee J, Ikei H, Song C, Himoro E, Miyazaki Y: The physiological and psychological relaxing effects of viewing rose flowers in medical staff [Article in Japanese, English abstract]. Jpn J Physiol Anthropol 2013, 18:1-7.

26. Ikei H, Lee J, Song C, Komatsu M, Himoro E, Miyazaki Y: Physiological relaxation of viewing rose flowers in high school students [Article in Japanese, English abstract]. Jpn J Physiol Anthropol 2013, 18:97-103.

27. Ulrich RS: View through a window may influence recovery from surgery. Science 1984, 224:420-421.

28. Park SH, Mattson RH: Effects of flowering and foliage plants in hospital rooms on patients recovering from abdominal surgery. Horttech 2008, 18:563-568.

29. Park SH, Mattson RH: Ornamental indoor plants in hospital rooms enhanced health outcomes of patients recovering from surgery. J Altern Complem Med 2009, 15:975-980

30. Shin WS: The influence of forest view through a window on job satisfaction and job stress. Scand J Forest Res 2007, 22:248-253.

31. Pearson-Mims CH, Lohr VI: Reported impacts of interior plantscaping in office environments in the United States. Horttech 2000, 10:82-86.

32. Song C, Ikei H, Komatsu M, Lee J, Lee S, Park BJ, Kobayashi H, Miyazaki Y: Elucidation of individual differences in physiological responses concerning forest therapy based on the low of initial value [Article in Japanese]. Jpn J Physiol Anthropol 2012, 17:38-39.

doi:10.1186/1880-6805-33-6

Cite this article as: Ikei et al:: The physiological and psychological relaxing effects of viewing rose flowers in office workers. Journal of Physiological Anthropology 2014 33:6.

\section{Submit your next manuscript to BioMed Central and take full advantage of:}

- Convenient online submission

- Thorough peer review

- No space constraints or color figure charges

- Immediate publication on acceptance

- Inclusion in PubMed, CAS, Scopus and Google Scholar

- Research which is freely available for redistribution

Submit your manuscript at www.biomedcentral.com/submit 